\title{
Formation of Computational Thinking Skills Using Computer Games in Teaching Mathematics
}

\author{
Elena V. Soboleva ${ }^{1 *}$, Elvira G. Sabirova ${ }^{2}$, Nigina S. Babieva ${ }^{3}$, Marina G. Sergeeva ${ }^{4,5}$, \\ Julia V. Torkunova ${ }^{6}$ \\ ${ }^{1}$ Vyatka State University, 610000, Moskovskaya Street 36, Kirov, RUSSIA \\ ${ }^{2}$ Kazan (Volga region) Federal University, 420008, Kremlevskaya Street 18, Kazan, RUSSIA \\ 3 I.M. Sechenov First Moscow State Medical University (Sechenov University), 119991, Trubetskaya Street 8, Moscow, RUSSIA \\ ${ }^{4}$ Research Institute of the Federal Penitentiary Service of Russia, 125130, Narvskaya Street 15a, Moscow, RUSSIA \\ ${ }^{5}$ Peoples' Friendship University of Russia (RUDN University), 117198, Miklukho-Maklaya Street 6, Moscow, RUSSIA \\ ${ }^{6}$ Kazan State Power Engineering University, 420066, Krasnoselskaya Street 51, Kazan, RUSSIA
}

Received 2 April 2021 - Accepted 7 June 2021

\begin{abstract}
The research is relevant as educational computer games are included in students' mathematical activity and form additional opportunities to improve the quality of teaching mathematics in a digital school, to support the formation of the demanded professional competence computational thinking. To form the appropriate skills that determine the essence of special computational thinking, the authors propose to include game educational spaces based on digital gamification resources into students' mathematical activities. The research aims to resolve the contradiction between requirements of the modern economy for specialists' high level of computational thinking and an insufficiently developed methodological base for training graduates that meets these requirements. The purpose of this research is to study the features of using gamification technologies in teaching mathematics to form the skills and abilities that make up the essence of computational thinking. The article describes directions of educational and cognitive mathematical activity based on the principles of gamification. The authors clarify the concept of "computational thinking", which includes a system of actions for activating patterns, connections between them from human memory, and compile an effective algorithm for solving them: to obtain relevant information on advanced technological developments; to state the problem and model; to use a software product with mathematical content.
\end{abstract}

Keywords: digital technologies, educational space, algorithm, gamification, game world with mathematical content, HTML 5 language, thinking process, challenges of the future

\section{INTRODUCTION}

\section{The Relevance of the Problem}

Preparing qualified personnel is one of the key areas of increasing the country's competitiveness. This fact is noted in the Strategy for the Development of the Information Society in the Russian Federation for 20172030, in the federal program "Human Resources for the Digital Economy" (Karakozov \& Ryzhova, 2019; Kuzminov, Sorokin, \& Froumin, 2019; Sirazetdinov,
2018), etc. In order to develop professional competencies of future specialists required in the digital society, it is necessary to develop and implement new approaches in education (Alexandrov, Ivaniushina, \& Simanovsky, 2017; Bayanova et al., 2019; Janelli, 2018; Galiullina, 2018; Soboleva et al., 2020; Zharko, 2020). A global trend in the field of modern mathematics education is the focus of teaching on the development of students' computational thinking skills (Barr \& Stephenson, 2011; Buteau, Sacristán \& Muller, 2019). Khenner (2016) defines computational thinking as a thinking process when

(c) 2021 by the authors; licensee Modestum. This article is an open access article distributed under the terms and conditions of the Creative Commons Attribution License (http://creativecommons.org/licenses/by/4.0/).

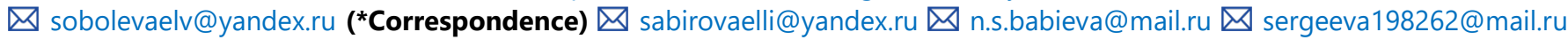
菏 torkynova@mail.ru 


\section{Contribution to the literature}

- The authors have clarified the concept "computational thinking", which includes a system of actions to activate patterns from human memory, connections between them; statement of the problem, taking into account the uncertainty of the future; making up an effective solution algorithm using digital technology tools.

- The authors have described directions of educational and cognitive activities in mathematics based on the principles of gamification: obtaining up-to-date information on advanced technological developments; problem statement and modeling; creation of your own software product.

- They have formulated didactic principles for including computer games with mathematical content in order to facilitate students' cognitive activity, support professional self-determination, and develop systemic and critical thinking.

- The authors have offered special material for improving methods, means, organizational forms of education, focused on forming computational thinking as the basis for future professional skills.

- They have generalized conditions affecting the formation of computational thinking: obtaining relevant scientific and theoretical facts, patterns, information on innovative methods and tools; their reasoned choice, effective implementation at a high technical level; analysis of the result and its practical application.

- The authors have identified possible problems of implementing the approach in the organization of students' research activities on the development and application of computer games with mathematical content, focused on the intellectual development.

formulating a problem and solving it, presented in a form that can be effectively implemented using information processing tools. The introduction of information and communication technologies affects all spheres of society, therefore, the desire to explore the possibilities of new digital means becomes a condition for developing a modern person (Hamada \& Hasan, 2017). Using computer devices effectively required digital tools in solving problems with mathematical content and computational thinking skills. Moreover, UNESCO defines principles for using artificial intelligence in mathematics education, coding activities and forming computational thinking (Hsu, Irie, \& Ching, 2019; Gault, 2019). This activity requires skills to enable everyone to code and solve problems using different algorithms. Moreover, realities of the modern educational environment require a digital schoolteacher who includes game elements and gamification services in educational and cognitive mathematical activities (Barbieri, Barbieri, \& Capone, R2021; Karavaev \& Soboleva, 2017; Piralova et al., 2020). According to Ilomäki and Ilomäki (2018), in the educational game space additional opportunities increase the motivation of the learning generation $\mathrm{Z}$, promote cognitive activity, support professional self-determination, and develop systemic and critical thinking. Designing a gaming virtual world, developing algorithms for the behavior of characters and their activities, game strategies, writing code - all this fully corresponds to the essence of computational thinking (Klunnikova, 2019). Indeed, computational thinking uses logical and algorithmic approaches to formulating a problem, analyzing and solving it.

On the one hand, the development of computational thinking skills in teaching mathematics, including gamification tools, is an important factor in the successful professional self-realization of a graduate in a modern technological society. On the other hand, in Russia, the concept "computational thinking" has not been studied until recently. An exception is Henner, who in his research analyzes this concept from the stand point of foreign authors and notes its relevance for national education (Khenner, 2016). He points out that this term in practical terms aims to update the content and methods of teaching, contributes to increasing efforts to form meta-subject results of education.

Thus, there is a contradiction between the requirements of the modern economy for a high level of computational thinking of future specialists and an insufficiently developed methodological base for training graduates that meets these requirements. The research hypothesis is that including the practice of designing and developing computer games for educational purposes into students' educational and cognitive activities will contribute to forming actions that determine the essence of computational thinking.

\section{Goals and Tasks of the Research}

The purpose of this research is to study the features of using digital gamification resources for forming skills that constitute the essence of computational thinking as an important competence of future specialists, and to propose a methodological approach to organizing cognitive activity using computer games with mathematical content.

The main tasks of the research are:

- to study approaches to defining the concept "computational thinking"; 
- to clarify the sequence of actions characteristic of computational thinking and the most demanded in modern technological society;

- to identify capabilities of software tools and gamification resources for forming actions that determine the essence of computational thinking;

- to describe the implementation of the selected system of actions using the example of specific practice for developing a computer game world for educational purposes;

- to experimentally confirm the effectiveness of the proposed educational and cognitive activity for forming computational thinking skills.

\section{LITERATURE REVIEW}

\section{Analysis of Russian Scientific and Pedagogical Literature}

Including game elements and digital services in students' cognitive activity are relevant directions for developing the didactic system (Karavaev \& Soboleva, 2017). To confirm the objective need for forming graduates' computational thinking skills in a digital school by means of digital gamification resources, the authors have analyzed fundamental scientific works devoted to identifying the concept "computational thinking" and describing the didactic potential of software services and gamification tools in terms of developing thinking processes, analytical and algorithmic actions.

Varshavskaya and Kotyrlo (2019). underline that global digital transformation has a significant impact on the needs of society, business, and the state regarding demanded professions of the future $=$. However, in practice, schools and universities often prepare graduates without taking into account trends in longterm planning, competitiveness, uncertainty of the future (Arefeva, Muraveva, \& Valiullin, 2021; Nizamutdinova et al., 2019; Perminov, Gadjiev, \& Abdurazakov, 2019; Usol'tsev \& Antipova, 2019; Valeeva \& Shakirova, 2015). In this case, a significant role belongs to motivational, psychological, socio-economic, technical conditions for supporting the selfdetermination of a future specialist (Gruzdev et al., 2018; Petrova, 2021; Varshavskaya \& Kotyrlo, 2019). According to Khutorskoy (2017), the personality of the teacher, his understanding and ability to design a digital educational space that meets the challenges of global transformation, should have a leading role. The mentor of the digital school can and should choose innovative teaching technologies that maximally work to form the type of thinking and way of action demanded in a digital society (Skurikhina et al., 2018; Valeeva \& Bushmeleva, 2016; Zaripova et al., 2014).

Solodikhina and Solodikhina (2019) in their works prove that the era of digital transformation will demand specialists with the skills of forecasting and planning in the uncertain future, the ability to independently formulate a problem and offer the best option for its solution, the ability to develop an algorithm for a solution and implement it by software and hardware (Ponomarev \& Dezhina, 2016; Solodikhina \& Solodikhina, 2019). Soboleva et al. (2020) clarify that a future professional must also be able to shift a solution of a problem to a possible one in the future (Soboleva et al., 2020). All of these characteristics form the basis of computational thinking.

As Klunnikova (2019) notes, the term "computational thinking" is a borrowed one for domestic literature, science and practice. Computational thinking, according to Henner, involves mental activity in formulating a problem to make a computational decision (Khenner, 2016). Indirectly, certain components of computational thinking were considered by Russian scientists: mathematical components (Kholodnaya \& Gelfman, 2016) and algorithmic ones (Lebedeva \& Kostenko, 2017).

Analyzing approaches to developing computational thinking by means of digital technologies, we note three main directions in research: defining the essence of computational thinking as a cognitive thinking process (Kholodnaya \& Gelfman, 2016); a hybrid of other ways of thinking (Klunnikova, 2019); the use of information processing tools for modeling processes studied in other disciplines (Borissova, Keremedchiev, \& Tuparov, 2020). Borissova et al. note that working with the program and its interface contributes to forming user communication skills.

As noted earlier, Henner's ideas are innovative for Russia. He shows that the computational thinking process uses special methods of formulating a problem and includes principles such as abstraction, decomposition, generalization, pattern recognition to solve it (Khenner, 2016).

Modern researchers convincingly prove that including digital technologies based on the principles of gamification in educational and cognitive activities not only corresponds to the goals and challenges of the education system, but also makes it possible to prepare the demanded and competitive professionals of the future (Smirnov, Zykova, \& Tikhomirov, 2019). Soboleva and Perevozchikova (2019) prove that interactive quest rooms as organizational forms of cognition and educational technology is not the only option for gamification of the digital educational space, but it also contributes to the formation of intellectual competence of a person (Soboleva \& Perevozchikova, 2019). Karavaev and Soboleva (2017) analyze various gaming services and platforms that have a didactic potential in terms of developing relevant skills and abilities (Karavaev \& Soboleva, 2017; Sabirova et al., 2019). Subsequently, Soboleva highlights the principles of 
gamification, the implementation of which is necessary to achieve the desired educational and cognitive effect according to the challenges of the digital economy (Fazleeva et al., 2021; Soboleva \& Perevozchikova, 2019; Yurkin et al., 2020). The authors substantiate the need to use interactive digital tools in order to improve the quality of teaching mathematics in a personified educational space. The effectiveness of organizing the corresponding mathematical activity is determined by teacher's capabilities and skills in a digital school.

According to Urvanova (2018), high-quality teaching of mathematics in a digital school involves the active inclusion of interactive digital means in students' educational and cognitive activities. Their choice, application should contribute to increasing academic performance in mathematics, the realization of the creative abilities and cognitive interests of each student. This situation confirms the theory that digital literacy of a modern person necessarily includes a communicative component (Alexandrov, Ivaniushina, \& Simanovsky, 2017). These theses are proved by Semenykhina and Rudenko (2018). They explore experiment and information interaction in the development of mobile applications, game educational spaces. Other authors complement their ideas and substantiate that distance technologies, e-learning, interactive communication tools and activity methods should be used in teaching mathematics (Galimova et al., 2019). Urvanova (2018) also formulates the condition that innovative pedagogical technologies and modern digital resources should be the basis of the educational environment, adjusted to individual personality traits. The author proposes directions of interaction in order to promote the development of thinking abilities involved in formulating mathematical problems and their solution. Urvanova (2018) notes that in such a specially designed educational model, the student receives the maximum conditions for developing "the ability to learn."

Solodikhina and Solodikhina (2019) reasonably argue that an important direction in educational policy is the transition from "mass" education to personalized one. According to the authors, the main goal of personalized learning is to provide conditions for students' selfrealization.

The most comprehensive methodological approach to developing an educational model based on digital technologies is presented by Soboleva and Perevozchikova (2019). The authors conclude that the number of digital educational resources for the gamification of learning is constantly increasing (Soboleva \& Perevozchikova, 2019). However, in order to purposefully and methodologically effectively include the relevant services in the educational process, a teacher needs to know the principles and conditions of gamification of education. Moreover, a teacher should understand the range of educational tasks that can be solved with the help of electronic resources; determine methodological functions, types of educational activities that digital technologies support and initiate. The purpose of their research is to identify the effectiveness of interactive educational platforms for the gamification of learning.

Therefore, there is an objective need to analyze and generalize the experience of using modern interactive methods and gaming tools in teaching mathematics.

Thus, due to the fact that forming computational thinking of a highly qualified and competitive specialist is a priority of the modern educational space (Varshavskaya \& Kotyrlo, 2019), there is an objective need to realize the didactic potential of digital technologies (including the principles of gamification) for developing skills that define the essence of the corresponding thinking process.

\section{Analysis of Foreign Studies}

In foreign theory and practice the term "computational thinking" was first used by Papert (1993), who proposed using computers to incorporate programming ideas into everyday life. Subsequently, the author called it "procedural thinking" (Papert, 1996).

Computational thinking is considered Hotyat (1952) as thinking that includes many skills and abilities necessary for the development of computer programs. At the theoretical level, such concepts of computer science as algorithm, recursion, decomposition, optimization, etc. are also embedded in the concept of computational thinking (Barr \& Stephenson, 2011).

Chevalier et al. (2020) develop this idea and add that the solution in this case can be performed by a person or a machine, or, more generally, a combination of people and machines. Finkel (2017) notes that working in an educational information environment involves performing a sequence of actions characteristic of computational thinking: task analysis (formulating a task as a computational problem); decomposing the problem into small logical steps; algorithm development (definition and refinement of the steps required to reach a solution); analysis and evaluation of this algorithm.

According to Bocconi, Chioccariello, and Earp (2018), the development of program learning is one of the priorities of modern mathematical education. The authors conclude that using computer technology can improve the quality of teaching mathematics (Wing, 2017). At the same time, scientists are conducting an experiment confirming that using intelligent learning systems, modeling and working with dynamic mathematical tools is much more effective than the usual multimedia course support (Bocconi, Chioccariello, \& Earp, 2018).

We have also analyzed the works devoted to studying issues of gamification of cognition and using 
digital technologies for designing an educational environment for teaching mathematics.

Ilomäki and Lakkala (2018) define trends in a digital school and the compliance of modern educational systems with these trends. Scientists explore the didactic potential of multimedia programs (combining text, sound and music, graphics, animation and still images) in teaching elementary mathematics. They use statistical data to substantiate the effectiveness of such multimedia applications for developing mathematical skills.

Bovermann and Bastiaens (2020) conclude that using interactive tools and applications at mathematics lessons provide variability in the tasks presentation, the uniqueness of exercises, an operational assessment of the performance, the necessary correction of the trajectory, a change in the complexity of the level, competitiveness and a game approach to learning. To create such applications, we use tools that are part of the integrated Microsoft Office and other applications that do not require programming skills (Bovermann \& Bastiaens, 2020).

Increasing mathematical literacy, forming a critical worldview is the basis for preparing future generations (Radović, Marić, \& Passey, 2019). Computational thinking in mathematical activity is revealed through a person's ability to argue his actions and ideas. Sayed (2017) investigates the nature of proof, various approaches to argumentation in the course of mathematical activity. The author shows the difference between mathematical proof and other sciences. An important role in assessing the formation of computational thinking is given to the assessment of literacy, mathematical language (Mora-Luis \& MartinGutierrez, 2020). Scientists notice that in modern mathematics education there is an increased attention to language as a tool for expressing thoughts with unique cognitive capabilities. The continuation of these ideas can be seen in modern scientific works (More, 2018; Paterson, 2017). The authors discuss the thesis that, through language, a person combines in consciousness the information received during spatial perception and mathematical activity (Záhorec, Hašková, \& Munk, 2010). Spatial cognition provides insight into the location of an object and information about its properties, such as color or size. Mathematical knowledge operates with numbers. Only language can integrate these contents into a coherent whole - the cognized (Zeynivandnezhad \& Bates, 2018).

Li, Mok, and Cao (2019) reasonably argue that computational thinking is one of the most important goals of mathematics education, as it can support sustainable studying mathematics. Their research summarizes the experience of teaching mathematics in Chinese schools.

The development of computational thinking involves an innovative approach to learning, the use of non- standard tools and technologies (Catarino et al., 2019). One of these can be gamification technology. Some works present the inclusion of game elements in arithmetic activity (Legaki et al., 2020).

According to Ghazali, Mutum and Woon (2019), education in school should take into account students' cognitive interests and professional aspirations. A digital learner, a generation $\mathrm{Z}$ teenager, most effectively perceives educational material that is presented in a form that he understands (Radović, Marić, \& Passey, 2019), for example, on a computer screen or smartphone. In this regard, computer games are most consistent with his psychological characteristics and style of thinking.

Yung et al. (2020) reasonably highlight a promising direction in the new educational realities - the use of game mechanics for supporting students' cognitive activity in the course of mathematics, based on the analysis and generalization of the didactic capabilities of QR codes for training, priorities for the development of web technologies and gamification services. Using gamification tools for modeling the processes and phenomena of the surrounding world, the construction of a mathematical model in a playful form helps to activate knowledge, increase the interest and curiosity of a teenager of generation Z (Yung et al., 2020). According to Yung et al. (2020) digital learning gamification resources are very effective in terms of supporting the formation of skills for independent mastering of new technologies and assessing their capabilities, existing in online and offline reality, constantly updating knowledge and acquiring new skills and competencies. The authors note that with the help of interactive methods, it is possible to increase mathematical performance, students' involvement in mathematical activities, thereby contributing to the personalization of learning. Incorporating interactive techniques stimulates critical and creative thinking.

Paiva et al. (2020) examine the general methodological aspects of organizing the learning process using modern interactive didactic tools. In their research, the concept "interactivity" means the interaction between objects. The authors formulate the following requirements for interactive teaching aids: support of motivation (increasing students' incentive to study the subject); management and regulation (direction of students to study objects, phenomena). Scientists note the following didactic properties of interactive teaching aids: multimedia, instrumental, adaptive, informative, motivational.

Bovermann and Bastiaens (2020) describe game mechanics, design features of game educational spaces: plot component; requirements for choosing the content of the world; the specifics of the task system; the need to train qualified game teachers; emotional design, supported by the rules for scoring points, a rating system. Yung et al. (2020) consider the design and 
development of educational computer games in relation to teaching mathematics.

But the greatest potential in terms of developing computational thinking has educational, cognitive, search activity in a programming environment, which involves obtaining fundamental theoretical knowledge in mathematics in a playful way. By including game elements, changes are made not only in the presentation of educational material, but also a positive emotional background is maintained, stress factors are minimized when solving mathematical problems (Buteau, Sacristán, \& Muller, 2019; Zeynivandnezhad \& Bates, 2018). The authors argue that work in a specially designed learning environment based on interactive technologies contributes to the acquisition of high-quality mathematical education by graduates of a modern school, as an integral part of any education, and skills of demanded mathematical thinking. Scientists describe a holistic process from motivation to the results presentation of mathematical programming activities.

Paiva, Leal, and Queirós (2020) also convincingly prove that the activity of compiling mathematical models, algorithms support the development of analytical skills. The importance of the ability to critically evaluate the result obtained and to work in conditions of uncertainty of the future is substantiated by Hotyat (1952). Moreover, if applied correctly, this approach can qualitatively increase the efficiency of mastering the educational material and activate students' cognitive activity, and contribute to professional self-realization (Helmlinger et al., 2020).

However, according to the analysis of the literature, there are certain difficulties in the practical implementation of game mechanics in teaching mathematics, the use of software applications that take into account the principles of didactics and contribute to the formation of computational thinking of students (Hsu, Irie, \& Ching, 2019). There is a need to allocate additional time and labor resources, work with educational mathematical content of the application, know the basics of didactics and their application in practice, choose software (Bocconi, Chioccariello, \& Earp, 2018), organize information interaction in the game environment, justify the need to include such forms of work in training, etc.

Thus, summarizing the results of the analysis of foreign literature, we formulate the following conclusions: digital resources of gamification have the didactic potential for forming skills and abilities that make up the essence of computational thinking, as an important competence of future specialists.

This research presents a methodological approach to the organization of cognitive activity on using computer games with mathematical content. It takes into account both the principles of didactics and generalized methods of action that maximally work to form students' computational thinking.

\section{MATERIALS AND METHODS}

\section{Theoretical and Empirical Methods}

To obtain theoretical generalizations, the authors have analyzed scientific works on the problem of defining the phenomenon of "computational thinking" and used digital resources of gamification in teaching mathematics.

The systemic activity approach is used as the main research method. The system of activity is analyzed in a virtual gaming environment supported by an appropriate software tool: using the functionality of a digital resource of gamification for data analysis, problem setting, building an information and mathematical model, developing an optimal solution algorithm and its effective implementation on a computer.

The stages of the related activity are described using the example of designing and developing computer games with mathematical content using HTML 5 tools. This specification is chosen because it provides innovative interfaces for application programming, making web pages richer, faster, or uncertain.

The research methodology is complemented by principles of the teaching gamification methodology: voluntary game, plot development algorithms as a reaction to the player's actions, logic and transitions between levels; system of rewards, points, ratings, etc.

The ideas of structured programming (developing programs "top-down"; splitting into subroutines, using basic algorithmic constructions) are the basis of students' cognitive activity. The stepwise refinement method is used for writing, debugging, and maintaining programs. The implementation of programming methods and tools when including game mechanics in training is supported by the following system of didactic principles: accessibility, consistency, connection between theory and practice, conscious activity, individual approach, cooperation.

The interface approach to training is implemented due to the fact that the user in a playful way integrates into the information environment of the training system. To communicate with objects of the environment, the student uses the menu, tools, working field, command field, turtle forms.

To obtain relevant information about the qualitative changes in students' educational achievements, we use empirical methods: observation, analysis of the results of work in the HTML 5 environment (user interface, game design, choice of algorithmic constructions, etc.).

When designing and developing computer games with mathematical content, we took into account 
principles that determine the essence of computational thinking: decomposition; abstraction; highlighting patterns; creation of an algorithm.

Special entry and final tests were developed and carried out, including 5 problems (each was assessed from a maximum of 3 points). Statistical processing of the research results was carried out using the Student's t-test. Due to the fact that the study is aimed to confirm the effectiveness of using digital technologies for developing skills that determine computational thinking, MS Excel has been chosen as a tool for statistical processing of results. The software tool allows to develop an information and computer model, support writing code in the form of a formula, implement an algorithm and automate calculations.

\section{The Research Base}

Approbation, generalization and implementation of research results are carried out:

- by teaching the courses "Information technologies in pedagogical activity", "IT in the processing of educational achievements and scientific research", "Technologies for creating educational programs" for training students in the field 44.04.01 Pedagogical education (Master's degree) based on materials developed by the author (Soboleva et al., 2017); the course has been taught since 2016 at the Vyatka State University;

- by teaching the course "Theory and methods of teaching Informatics" for training students in the field 03.44.05 Pedagogical education (two profiles) based on materials developed by the author (Soboleva et al., 2017); the course has been taught since 2010 at the Vyatka State Humanitarian University, since 2016 - at the Vyatka State University;

- when organizing training in computer science at the Kirov Lyceum of Physics and Mathematics.

Evaluation of the effectiveness of students' cognitive activity in the development of computer games with mathematical content was carried out during the pedagogical experiment.

To formulate the content of the tasks system, to design a computer game world for educational purposes, 13 undergraduates were involved in the field 04.01.51 Mathematics and Computer Science, Vyatka State University (Kirov). The approbation was carried out on the basis of the Kirov Lyceum of Physics and Mathematics, when teaching mathematics in grades 5-6.

The average age of the respondents was 12 years. In total, 26 schoolchildren (48\% of girls and $52 \%$ of boys) took part in the experiment.

The statistical analysis of the reliability of the results of the pedagogical experiment was assessed on the basis of processing the data obtained by the Student's tcriterion.

\section{Research Stages}

The research had three stages.

The preparatory stage of the experiment clarified the sequence of actions characteristic of computational thinking and the list of skills that are most in demand in modern technological society. To assess the input conditions, we used the materials of a specially organized test, taking into account the priorities of the digital society, the competence of new professions. All questions and tasks were developed by the authors in accordance with the requirements of state federal educational standards. During the test students had to solve 5 problems. A student received 3 points for the correct and complete solution of each problem.

Thus, the maximum possible number of points was 15. If the student received more than 13 points, the level of the studied skills and abilities was defined as "high"; the range from 6 to 12 points corresponded to the "medium" level, other results were of the "low" level

The second stage determined directions of educational and cognitive activities for the design and development of a computer game world for educational purposes using programming language tools; maximally working on developing skills of independent mastering new technologies and assessing their capabilities, interaction in virtual game reality, constant updating of knowledge. The corresponding activity was accompanied by work with complex systems and large amounts of data.

The third phase of the study was the experiential teaching and application of HTML 5 tools to shape the skills making up the essence of computational thinking.

\section{RESULTS}

\section{The Main Provisions of the Methodology}

The authors propose their own approach to the interpretation of the concept "computational thinking". They use this term to describe cognitive activity, which involves the implementation of the following sequence of actions: activating from a person's memory a system of objects images, connections between them; stating the problem taking into account the uncertainty of the future; developing a solution algorithm and its effective implementation by tools of the software environment. The proposed approach takes into account all the characteristic elements that determine the essence of the phenomenon "computational thinking" and constitute the basis of mathematical education.

Moreover, we believe that a specialist of the future with the formed skills of computational thinking, should be prepared to carry out activities on the design, creation and use of innovative information and computer technologies in solving a wide range of scientific, mathematical, technical, economic and management 
problems. Based on the requirements of society, government and business, we reasonably conclude that highly qualified personnel of the digital economy should be ready to use software tools for information processing (including gamification services) in their research, mathematical and design developments. The most important component of such training is using digital technologies for teaching mathematics, obtaining the necessary mathematical research experience, and applying it in practice.

The proposed approach to include digital gamification resources in teaching mathematics is focused on mastering practical techniques, functional capabilities of game mechanics, computer game technologies, and defining a methodologically scientific base.

The game world with mathematical content within the framework of the presented research is considered as a digital model for solving an educational problem of a problematic nature, built on the principles of game mechanics and fundamental mathematical theory.

The synthesis of scientific and theoretical knowledge and the applied nature of activities to develop a game world with mathematical content helps support a competitive graduate of a digital school in an uncertain future when navigating promising innovative developments, their development and effective application to solve a wide range of mathematical problems.

Thus, the design and filling of the game mathematical educational space with HTML 5 means contribute to improving the quality of the obtained subject and general educational knowledge, and to developing computational thinking. In the course of educational and cognitive activities, in the process of decision-making and independent choice, the following soft skills that are in demand by the digital society are formed: planning, search, critical assessment and processing of information, the ability to work in an uncertain future, responsibility.

\section{Educational Activities for the Design and Development of Computer Games with Mathematical Content}

To form the skills and abilities that define the essence of computational thinking, the authors chose the HTML 5 language as a means of digital gamification resources. Technically, it is not just a formalized way of writing an algorithm according to certain rules and syntax. Moreover, it is not only a collection of commands, operators and their meanings. At the methodological level, it is an additional language, which presents the content of the virtual space, intuitively understandable and emotionally attractive to the user (learning generation Z). This content may include images, videos, animations, communication tools. On a practical level,

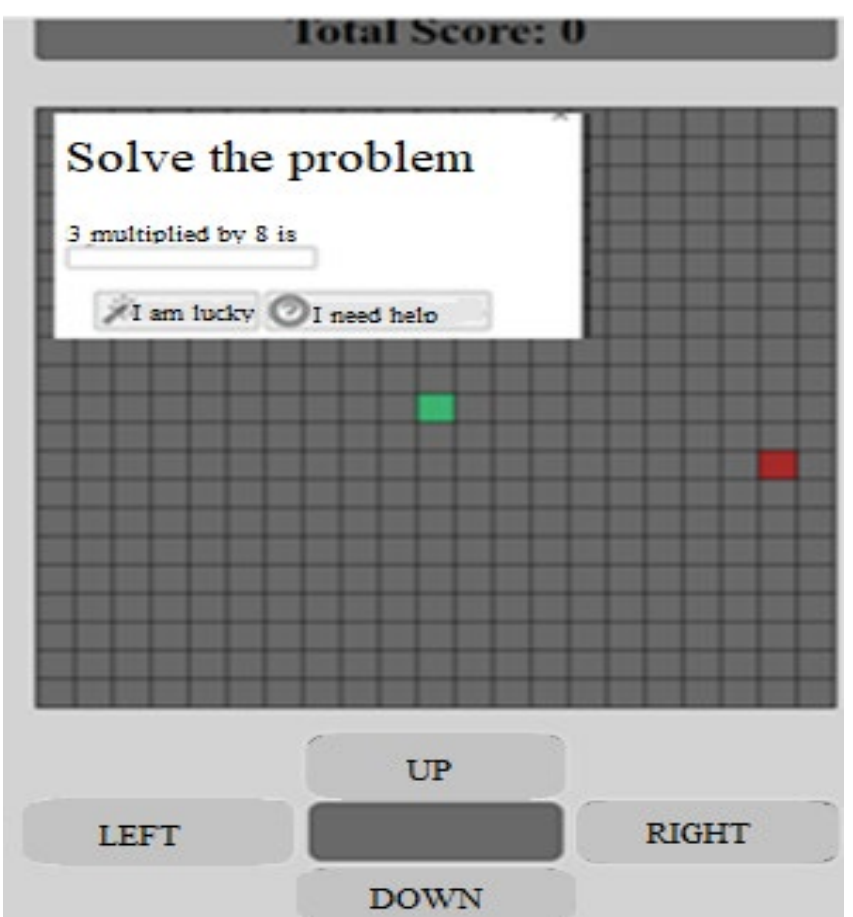

Figure 1. Educational math game

HTML 5 allows to link the transmitted educational information with channels of perception. As a consequence, it has a powerful didactic effect. Manipulating virtual objects through games, the student carries out educational and cognitive activities and gains skills that are in demand in the digital society of the present and future.

Figure 1 shows an example of an implemented game educational space with mathematical content, focused on the development of computational thinking.

While implementing, the authors took into account both didactic principles and game mechanics:

1. Consistency in the transfer of mathematical material (breaking complex tasks into simpler ones without losing motivation to study a particular topic).

2. The principle of gradual complication. Involving students in the mathematical process begins with simple tasks. In order to feel progress and movement forward, being in a dynamic state of thinking, it is necessary to gradually increase the complexity of tasks for a user. Only in this case, educational, cognitive and mental activity, expressed through a sense of progress, gives pleasure, involves in the educational game space with mathematical content. At the same time, the number of simple tasks should be limited in order to avoid a quick loss of interest and to form an understanding of the need to make efforts to achieve the desired goal. The latter can be not only ratings, points, awards, but also the acquisition of social status and recognition in the group.

3. Inclusion of math problems of the "puzzle" type, which seem difficult at first, but suggest an obvious solution. The HTML and CSS code in this case can be publicly available, but students need to choose the 
appropriate commands / operators to solve the puzzle. Most theoretical problems of a mathematical nature take on a new look and motivate to search, to make a scientific discovery.

4. Instant feedback, which means that the learner receives an immediate response from the program after running the code. This reaction can be implemented through outputting a result, receiving a message, visual effect, etc. The implementation of the principle allows to reduce the cost of an error when writing code, since when completing an assignment, a participant works in small iterations. Moreover, there is also the effect of vocational guidance. Indeed, the learner gains hands-on experience similar to how programmers work. The skills and abilities of step-by-step detailing of the program, debugging and testing are formed. As a methodological complexity, we point out the fact that a student can spend a large amount of time while the way to solve a mathematical problem is already clear.

5. Game mechanics "Storytelling", which involves combining a system of mathematical problems with a common idea or scenario for educational purposes. For example, when studying the rules for calculating derivatives in a mathematics course, after passing all the levels and tests of the game world, participants receive a Memo. As a result, obtaining complex theoretical material is supported by an emotionally attractive game situation (for example, to save the world / girl and obtain superhero status).

6. The principle of scoring, changing the rating to improve the status in the game space. All the previously mentioned researchers of gamification of education necessarily note this condition. Only when this condition is performe, the desired didactic effect is achieved.

7. Game mechanics "Open profiles", which allows community members to view the profiles of other learners. This access allows to maintain competitiveness, compare achievements, motivate and encourage users to acquire new mathematical knowledge.

The role of a teacher when using the practice of designing computer games with mathematical content include the following stages (methodological component):

1) explaining fundamental theories for the accumulation of information about a mathematical object, phenomenon, laws;

2) organizing practice-oriented activities for the systematization of the data obtained in order to identify the essential information necessary for building a game educational space, that is, a model of the computer world;

3) developing a system of mathematical problems, the solutions of which will guide the player when moving around the game world;

4) developing a system of cognitive tasks, which means the completion of mathematical research;
5) organizing practice-oriented activities to check and correct the results obtained in the study of the game educational space with mathematical content.

The stages of the teacher's activity must necessarily take into account the following principles: consider the individual, age, psychological and physical characteristics of students; application of universal methods, approaches that are the basis of research, educational and other professional activities of students; focus on developing skills of independence in decisionmaking, responsibility for one's choice and its consequences; formation of the basis of self-education; creating situations of success; organization of creative activity.

When designing an educational environment focused on forming computational thinking with gamification resources, the authors noted the following features that maximally contribute to improving the quality of educational results in mathematics:

1. Correlation of the educational goal (here in mathematics) and the results of educational and search activities in the gaming environment. First of all, before using a game application that supports interaction and a nonlinear trajectory of cognition, it is necessary to determine the goals and expected results (personal, subject, metasubject): students must remember mathematical facts, get logical conclusions, choose a reasoned answer, build their personal educational route from "ignorance to knowledge". The goal determines the content of the game project and the number of necessary tools, plot branches, levels of material presentation.

2. Understanding and taking into account the individual, age, psychological and physical characteristics of students.

3. Determination of the place and significance of the game application for the basic course in mathematics: where and when the resource is used, its duration.

4. Designing the plot of a mathematical game for educational purposes. The plot for the game space (as in the described variant) can go beyond the limits of the studied discipline. The plot of a novel can be based on a literary work, film events, historical or geographical discovery.

5. The choice of the text component, ie. features of drawing up a system of tasks and questions. We advise to adhere to the following recommendations: arrange tasks and questions in ascending order of difficulty; the first problem (the starting point of the game) is the simplest, containing only known mathematical facts and firmly learned formulas; the wording should be understandable for students, consistent with their cognitive interests and level of academic achievement. 


\section{Experimental Evaluation}

\section{The ascertaining stage of the experiment}

At the first stage of the experiment, to assess the input conditions, the authors used materials of a specially organized test, taking into account priorities of a digital society, the competence of the atlas of new professions. All questions and tasks were developed by the authors in accordance with the requirements of state federal educational standards. In the test students had to solve 5 problems. A student got 3 points for the correct and complete solution of each problem.

1. Harry Potter flew on a broom $4 \mathrm{~km}$ towards the castle after the "Snitch". At the same time, the wind helped him to overcome the distance. However, the tricky ball turned 180 degrees abruptly. And for another $33 \mathrm{~km}$, Harry raced after it, overcoming the resistance of the air. The game lasted one hour. Find the broom speed if the wind speed was constant at $6.5 \mathrm{~km} / \mathrm{h}$.

2. Children of Captain Grant were looking for their father for a year. At the same time, they covered $4 \mathrm{~km}$ on foot, $33 \mathrm{~km}$ sailed on the Duncan ship along the equator forward and $6.5 \mathrm{~km}$ when returning back. Determine the speed of the travelers.

To solve the fourth task, a student had to compose an equation on his own. For example, a cruise ship covered $108 \mathrm{~km}$ along the river and $84 \mathrm{~km}$ upstream, spending 8 hours for the entire journey. It is known that the speed of the river is $3 \mathrm{~km} / \mathrm{h}$. Find your own boat speed. Having denoted the own speed of a cruise ship through $\mathrm{x} \mathrm{km} / \mathrm{h}$, write an equation corresponding to the condition of the problem.

3. How do I get to the Ravenclaw faculty living room? Climbing the spiral staircase, you will find yourself in front of a door that has neither a handle nor a keyhole: a solid canvas of ancient wood and a bronze eagle-shaped knocker. Knock on the door knocker and you will hear a question. The correct answer will serve as a password that will take you inside. Each time you will be asked a new question. Now the question sounds like this: "I will name one four-digit number N. Using it, you need to compose another number $M$. To get the number $M$, you need to swap the number of hundreds with the number of ones and the number of tens with the number of thousands in the number $\mathrm{N}$, then add the sum of all figures". Write an algorithm to determine the number $\mathrm{M}$ by the entered number $\mathrm{N}$.

4. From the list of professions suggested by a teacher, make a rating of the most demanded in Russia. For example, a mechanic, tutor, sales manager, design engineer, driver, doctor, accountant, mobile app developer, big data analyst, game educator. Or, another option, the sequence is given: "GAMES", "D:", "Snake.rar", "This computer", "Puzzle games". You need to arrange the elements correctly in the right order so that the user can find the desired file.
5. The fifth task involves the use of software and information technologies. For example, Hermione decided to organize a picnic for her friends. To do this, she compiled a "memo", where she wrote down all the purchases necessary for a good rest (food, dishes, their quantity, etc.). Hermione, like a real researcher, solved the task in a complex way: the girl studied all the prices in magic stores and shops. For structuring, she created a spreadsheet with a range of prices for each item. Determine in which shop Hermione's costs are minimal.

Thus, it was possible to collect experimental data on 26 students in grades 5-6. As a result of the preliminary control event, we revealed an almost identical initial level of preparedness of students - participants in the pedagogical experiment. We can consider them as a general sample of 26 people. The average age of the respondents was 12 years. In total, 26 students (48\% of girls and $52 \%$ of boys) took part in the experiment.

The statistical analysis of the reliability of the results of the pedagogical experiment was assessed based on the processing of the data obtained by the Student's tcriterion.

\section{Forming stage of the experiment}

Classes for students in the control group were conducted according to the traditional teaching method of learning the basics of algorithms and programming, without a special organization of cognitive mathematical activity. They were active and independent in research, which was organized in the form of practical work with mobile technologies, completing assignments on specific topics. Students from the experimental group were taught according to the described option.

At the stage of the forming experiment, the teacher analyzed the requirements of the digital economy for students in engineering and technical fields. The provisions of the current state federal educational standards determine it. Within the framework of general professional competencies, a student must be able to advise and use fundamental knowledge in the field of computer science in professional activities; find, analyze, programmatically implement and use mathematical algorithms in practice, including the use of modern digital technologies.

In connection with the outlined requirements for the level of skills that determine the essence of computational thinking, we determined the following levels.

The "high" level corresponded to situations if the student was independent in setting the task, identifying objects, phenomena and interrelationships between them in the subject area of the research problem; compiled informational, mathematical and computer models without errors; applied the method of step-bystep detailing when compiling an algorithm, performing the necessary analytical and synthetic operations; 
Table 1. Results of the experiment

\begin{tabular}{lccccc}
\hline No & Before the experiment & After the experiment & № & Before the experiment & After the experiment \\
\hline 1 & 11 & 15 & 14 & 5 & 9 \\
2 & 9 & 14 & 15 & 9 & 10 \\
3 & 10 & 8 & 16 & 10 & 15 \\
4 & 15 & 14 & 17 & 11 & 15 \\
5 & 3 & 3 & 18 & 9 & 15 \\
6 & 9 & 13 & 19 & 1 & 6 \\
7 & 3 & 10 & 20 & 2 & 9 \\
8 & 10 & 11 & 21 & 3 & 8 \\
9 & 9 & 14 & 22 & 4 & 11 \\
10 & 2 & 8 & 23 & 10 & 15 \\
11 & 8 & 10 & 24 & 11 & 14 \\
12 & 6 & 11 & 25 & 10 & 14 \\
13 & 4 & 9 & 26 & 11 & 14 \\
\hline
\end{tabular}

technically competently and rationally approached the recording of the algorithm in the software implementation environment; critically assessed the result obtained and made appropriate adjustments to the decision model.

The "average" level was defined if the student could formulate the problem at the required level of abstraction, highlight the objects of modeling and their essential properties only with outside help; made one or two non-critical errors in modeling; the technical implementation of the algorithm was not optimal, but led to a solution; could not always critically evaluate the result obtained, but when indicating shortcomings, made appropriate adjustments to the model.

In all other cases, the level of computational thinking was defined as "low".

Then the authors conducted classes in mathematics, organized electives, research and project activities for working with computer games, including mathematical tasks. In the course of designing gaming educational worlds with mathematical content, students acquired skills and abilities that made up the essence of computational thinking.

Studying was carried out in the following mode: learning the basic concepts of game theory and constraints associated with mathematical formalization; strategies and game mechanics. Next, the solution of mathematical problems on strategies took place, tasks were carried out to compile information and computer models, and then their implementation by means of a programming language. An obligatory stage of the work was the analysis and discussion of the results. Then students of the experimental group were offered possible topics of projects for developing educational game worlds ("Quest for the professions of the future", "The Flying Dutchman", "Journey to Neverland", etc.), they chose those that corresponded to their professional aspirations, cognitive interests, abilities, educational achievements. They started to implement software after studying the relevant theoretical material on the theory of games and on the principles of didactics.
Then they studied the specifics of the HTML 5 language and the software implementation of algorithmic constructions. They were given one or two months for the practical implementation of the concept / idea of a computer game for educational purposes. Technically, HTML 5 is not just a formalized way to write an algorithm according to certain rules and syntax. Moreover, it is not only a collection of commands, operators and their meanings.

At the methodological level, HTML 5 is an additional language that presents the content of a virtual space, intuitive and emotionally attractive to the user (learning generation Z). This content may include images, videos, animations, communication tools. At a practical level, HTML 5 allows to link the transmitted educational information with the channels of perception. As a consequence, it has a powerful didactic effect. Manipulating virtual mathematical objects through games, a student carries out educational and cognitive activities and gains skills that are in demand in the digital society of the present and future. Using HTML 5 in the implementation of a gaming space with math content is in line with the priorities in digital technology and math education. Its application allows to convincingly show the didactic potential of game mechanics, in particular, for forming computational thinking. Let us formulate a hypothesis:

H0: The level of skills that form the basis of computational thinking has remained unchanged after including the practice of designing and developing computer games with mathematical content by means of gamification resources in students' educational and cognitive activities.

H1: The skills and abilities that form the basis of computational thinking have increased.

Performing a quantitative analysis of the above results, we can conclude that after the experiment, $46 \%$ of students have a high level of skills and abilities that form the basis of computational thinking, while initially this percentage was $4 \%$. The proportion of students, with 
an initially low level of computational thinking, has qualitatively decreased from $35 \%$ to $4 \%$. It can be argued that most participants are those respondents who initially had an average level, i.e. made mistakes in analytical activity, at the level of making a mathematical decision, arithmetic calculations, recording the answer / code and when evaluating the result.

\section{Control stage of the experiment}

Analysis of the data using the one-sample Kolmogorov-Smirnov test showed that the distributions did not differ from the normal: $\mathrm{z}_{\text {before }}=1.192(\mathrm{p}=0.116>$ $0.05)$ and $z_{\text {after }}=1.066(p=0.206>0.05)$. The statistical analysis of the reliability of the results of the pedagogical experiment was assessed on the basis of processing the data obtained by the Student's t-criterion. According to the calculation algorithm using MS Excel, the empirical value of the criterion was calculated $\left(\mathrm{t}_{\mathrm{emp}}=8.2\right)$. According to the tabular values for the significance level $\mathrm{a}=0.05$, the critical value of the statistics is $2.06\left(\mathrm{t}_{\text {crit }}=\right.$ 2.06). Thus, we got that $t_{\text {emp }}=8.2>t_{\text {crit }}=2.06$. Therefore, $\mathrm{H} 0$ is rejected and hypothesis $\mathrm{H} 1$ is accepted. In other words, the activity of developing a gaming educational space with mathematical content and digital gamification resources has contributed to the development of computational thinking.

\section{DISCUSSIONS}

The sample of students was not probabilistic; for diagnostics, the results of the input control event were taken into account. The selection of participants for the experiment and the sample size were based on the specifics of the research: the study of game theory, the principles of gamification and their implementation by means of digital technologies. Throughout the experiment, work on the design and development of an educational game space by means of HTML 5 was carried out by the same teacher, on the same software equipment in special classes of the lyceum. The implementation took into account the peculiarities of mathematical education, didactic principles and game mechanics.

So, the described system of actions for the development of a game educational space with mathematical content allows:

- to build computational skills;

- to gain experience in design research and mathematical activities;

- to apply theoretical information to solve applied mathematical problems;

- to simulate work in demanded professions.

Thus, a graduate of a digital school becomes competitive and maximally prepared for the challenges and uncertainties of the future.
The use of HTML 5 in the design and development of a gaming educational space with mathematical content meets the priorities in the field of digital technologies, and allows to convincingly show the didactic potential of game mechanics, in particular for forming computational thinking.

The work on the design and filling of the educational game space with HTML 5 means in the experimental group was aimed to form a set of the following educational results in mathematics:

- subject (arithmetic and logical operations, rounding and use of alphabetic symbols, building graphs of functions and tables, use of scientific mathematical terminology, etc.);

- metasubject (universal principles and patterns, tools for modeling phenomena and processes; understanding the areas of application of mathematical knowledge and skills in a digital society; simple and complex conditions; working with a problem formulation; search, presentation and storage of information; inductive and deductive ways of reasoning; algorithmic nature of activities in an interactive environment, etc.);

- personal (formation of a sense of responsibility to other users for the reliability of information; development of critical thinking and creative abilities of students in the analysis and generalization of information in the course of solving problems; support for independent choice in the game environment; use of digital resources for implementing educational and cognitive goals and self-development, etc.);

The findings on the didactic potential of digital gamification resources in relation to improving the quality of learning, forming computational thinking are confirmed by the results of Klunnikova (2019). A significant result of the research is the description of the basic ideas of the approach that expand the ideas of Paiva et all. (2020) about the possibilities of languages and programming tools for developing such thinking processes as decomposition; abstraction; selection of images; algorithm development.

The fact that the concretization of the content of each educational game space with mathematical content does not occur at teacher's initiative, which is typical for the traditional system of teaching mathematics, is of particular importance for solving future professional tasks for implementing innovations. The direction for mathematical research is determined by students themselves. When developing a gaming educational space with mathematical content, additional opportunities were also created for developing teamwork skills, cross-industry communication, and the propaedeutics of working with technical documentation. 


\section{CONCLUSION}

The study presents a solution to the problem caused by the need to expand the goals of the mathematical education system, to update tools and methods based on digital technologies. An appropriate digital learning environment should facilitate the activation of a sequence of images from a person's memory, support the process of setting a problem, drawing up an effective solution algorithm. For the formation of the appropriate skills that determine the essence of special computational thinking, the authors suggest to include the practice of developing game spaces with mathematical content by means of digital gamification resources in the system of students' mathematical activity.

The authors describe the sequence of educational and cognitive actions of a game nature, which assumes the experience of mathematical modeling, design and creation of your own software product. Scientific and theoretical facts, patterns and methods of mathematics, logic, game theory, etc. in the presented version are a necessary fundamental basis for high-quality training of a competitive professional of the future. An activation of knowledge, understanding of the fundamental scientific principles underlie all digital technologies.

In the presented system of educational and cognitive activities for the design of a virtual game world, it is important to obtain up-to-date information on advanced technological developments, digital means and resources; their reasoned choice, effective application at a high technical level; analysis of the obtained result and its practical application.

The software and hardware support is presented by the description of the system of work by means of the HTML 5 language. The effectiveness of the proposed approach is confirmed by a pedagogical experiment.

The research summarizes the conditions that affect the formation of computational thinking: obtaining relevant scientific and theoretical facts, mathematical laws, information on innovative methods and tools; their reasoned choice, effective implementation at a high technical level; analysis of the mathematical result and its practical application. Computational thinking uses a special method of formulating a problem and applies principles such as abstraction, decomposition, generalization, pattern recognition to solve it.

Thus, by designing and developing educational game projects, students acquire computational thinking skills. They learn how to use computers to solve mathematical problems, tasks of an applied nature, and make informed decisions using digital resources. In the digital age, it is necessary to develop students' computational thinking since it is an important competence that determines success and professional self-realization in a modern technological society.
The research materials can be used to improve the quality of mathematical education through specially organized areas of support for students' activities in the design and development of a game educational space with mathematical content, focused on their intellectual development and preparation for future professional activities.

Author contributions: All authors have sufficiently contributed to the study, and agreed with the results and conclusions.

Funding: This paper has been supported by the Kazan Federal University Strategic Academic Leadership Program.

Declaration of interest: No conflict of interest is declared by authors.

\section{REFERENCES}

Alexandrov, D., Ivaniushina, V., \& Simanovsky, D. (2017). Online educational resources for schoolchildren and the digital divide. Educational Studies Moscow, 3, 183-201. https://doi.org/ 10.17323/1814-9545-2017-3-183-201

Arefeva, E. V., Muraveva, E. V., \& Valiullin, B. M. (2021) Application of mathematical modeling in forecasting the spread of infection. Vestnik NCBŽD, 2(48), 82-92.

Barbieri, G. G., Barbieri, R., \& Capone, R. (2021). Serious games in high school mathematics lessons: An embedded case study in Europe. Eurasia Journal of Mathematics, Science and Technology Education, 17(5), em1963. https:/ / doi.org/10.29333/ ejmste/10857

Barr, V., \& Stephenson, C. (2011). Bringing computational thinking to K-12: what is Involved and what is the role of the computer science education community? ACM Inroads, 2(1), 48-54. https:// doi.org/10.1145/1929887.1929905

Bayanova, A. R., Kuznetsov, V. V., Merculova, L. V., Gorbunova, L. N., Pervozvanskaya, O. A., Shalamova, O. O., \& Vorobyova, C. I. (2019). Student performance interrelation with gadget use at lessons. Journal of Environmental Treatment Techniques, 7(3), 432-437. https://doi.org/10.31838 /jcr.07.13.20

Bocconi, S., Chioccariello, A., \& Earp, J. (2018). The Nordic approach to introducing computational thinking and programming in compulsory education. Report prepared for the Nordic@BETT2018 Steering. https:/ / doi.org/10.17471/54007

Borissova, D., Keremedchiev, D., \& Tuparov, G. (2000). Multi-criteria model for questions selection in generating e-education tests involving gamification. TEM Journal, 9(2), 779-785. https:// doi.org/10.18421/TEM92-47

Bovermann, K., \& Bastiaens, T. J. (2020). Towards a motivational design? Connecting gamification user types and online learning activities. Research and Practice in Technology Enhanced Learning, 15(1), 4-18. https:// doi.org/10.1186/s41039-019-0121-4 
Buteau, C., Sacristán, A. I., \& Muller, E. (2019). Roles and demands in constructionist teaching of computational thinking in university mathematics. Constructivist Foundations, 14(3), 294-309.

Catarino, P., Vasco, P., Lopes, J., Silva, H., \& Morais, E. (2019). Cooperative learning on promoting creative thinking and mathematical creativity in higher education. REICE. Revista Iberoamericana Sobre Calidad, Eficacia y Cambio En Educacion, 17(3), 5-22. https:/ / doi.org/10.15366/reice2019.17.3.001

Chevalier, M., Giang, C., Piatti, A., \& Mondada, F. (2020). Fostering computational thinking through educational robotics: A model for creative computational problem solving. International Journal of STEM Education, 7(1), 1-18. https:/ / doi.org/10.1186/s40594-020-00238-z

Fazleeva, E. V., Fazleev, A. N., Valeeva, A. A., \& Merkulov, A. N. (2021). Influence of physical education on the dynamics of psychophyiological adaptation indicators during distance learning. Vestnik NCBŽD, 1(47), 45-52.

Finkel, A. (2017). Cognitive analysis, digital psychology and training of university teachers. Pratiques Psychologiques, 23(3), 303-323. https://doi.org/ 10.1016/j.prps.2017.05.006

Galimova, E., Konysheva, A., Kalugina, O., \& Sizova, Z. (2019). Digital educational footprint as a way to evaluate the results of students' learning and cognitive activity in the process of teaching mathematics. Eurasia Journal of Mathematics, Science and Technology Education, 15(8), em1732. https:/ / doi.org/10.29333/ejmste/108435

Galiullina, E. R. (2018). Mastering the methods of generating ideas as a way to develop creativity. Vestnik NCBŽD, 1(35), 12-15.

Gault, F. (2019). User innovation in the digital economy. Foresight and STI Governance, 13(3), 6-12. https:/ / doi.org/10.17323/2500-2597.2019.3.6.12

Ghazali, E. M., Mutum, D. S., \& Woon, M. Y. (2019). Multiple sequential mediation in an extended uses and gratifications model of augmented reality game Pokémon Go. Internet Research, 29(3), 504-528. https:/ / doi.org/10.1108/IntR-12-2017-0505

Gruzdev, M. V., Kuznetsova, I. V., Tarkhanova, I. Yu., \& Kazakova, E. I. (2018). University graduates' soft skills: The employers' opinion. European Journal of Contemporary Education, 7(4), 690-698. https:// doi.org/10.13187/ejced.2018.4.690

Hamada, M., \& Hasan, M. (2017). An interactive learning environment for information and communication theory. Eurasia Journal of Mathematics, Science and Technology Education, 13(1). https://doi.org/ 10.12973/eurasia.2017.00603a

Helmlinger, B., Sommer, M., Feldhammer-Kahr, M., Wood, G., Arendasy, M. E., \& Kober, S. E. (2020).
Programming experience associated with neural efficiency during figural reasoning. Scientific Reports, 10(1), 13351. https://doi.org/10.1038/ s41598-020-70360-Z

Hotyat, F. (1952). The weakness in mathematical thinking in adolescents. Enfance; Psychologie, Pédagogie, Neuropsychiatrie, Sociologie, 5(4), 273-300. https:/ / doi.org/10.3406/enfan.1952.1247

Hsu, Y. C., Irie, N. R. \& Ching, Y. H. (2019). Computational Thinking Educational Policy Initiatives (CTEPI) across the Globe. TechTrends, 63, 260-270. https://doi.org/10.1007/s11528-01900384-4

Ilomäki, L., \& Lakkala, M. (2018). Digital technology and practices for school improvement: innovative digital school model. Research and Practice in Technology Enhanced Learning, 13, 25-34. https:/ / doi.org/10.1186/s41039-018-0094-8

Janelli, M. (2018). E-learning in theory, practice, and research. Educational Studies Moscow, 4, 81-98. https: / / doi.org/10.17323/1814-9545-2018-4-81-98

Karakozov, S. D., \& Ryzhova, N. I. (2019). Information and education systems in the context of digitalization of education. Journal of Siberian Federal University. Humanities \& Social Sciences, 12(9), 1635-1647. https://doi.org/10.17516/19971370-0485

Karavaev, N. L., \& Soboleva, E. V. (2017). Analysis of software services and platforms that have the potential to gamify learning. Scientific and Methodological Electronic Journal "Concept", 8, 461473. http:/ / doi.org/10.24422/mcito.2017.8.6960

Khenner, E. K. (2016). Computational thinking. The Education and Science Journal, 2, 18-33. https:/ / doi.org/10.17853/1994-5639-2016-2-18-33

Kholodnaya, M. A., \& Gelfman, E. G. (2016). Development-focused educational texts as a basis for learners' intellectual development in studying mathematics (DET technology). Psychology in Russia: State of the Art, 9(3), 24-37. https://doi.org/10.11621/pir.2016.0302

Khutorskoy, A. V. (2017). Methodological basis for the use of competence-based approach to the design of education. Vysshee obrazovanie v Rossii, 12(218), 8591. https://vovr.elpub.ru/jour/article/view/1228 /1047

Klunnikova, M. M. (2019). The methods of developing computational thinking of students while studying the course "Numerical methods" based on blended learning. Computer Science and Education, 6, 34-41. https: / / doi.org/10.32517/0234-0453-2019-34-6-3441

Kuzminov, Y., Sorokin, P., \& Froumin, I. (2019). Generic and specific skills as components of human capital: New challenges for education theory and practice. 
Foresight and STI Governance, 13(2), 19-41. https:/ / doi.org/10.17323/2500-2597.2019.2.19.41

Legaki, N., Xi, N., Hamari, J., Karpouzis, K., \& Assimakopoulos, V. (2020). The effect of challengebased gamification on learning: An experiment in the context of statistics education. International Journal of Human Computer Studies, 144, 102496. https:/ / doi.org/10.1016/j.ijhcs.2020.102496

Leontiev, D. A., Lebedeva, A. A., \& Kostenko, V. Yu. (2017). Pathways of personality development: following Lev Vygotsky's guidelines. Voprosi obrazovania, 2, 98-112. https://doi.org/10.17323/ 1814-9545-2017-2-98-112

Li, N., Mok, I. A. C., \& Cao, Y. (2019). The evolution of mathematical thinking in chinese mathematics education. Mathematics, 7(3), 297. https: / / doi.org/10.3390/m-ath7030297

Mora-Luis, C. E., \& Martin-Gutierrez, J. (2020). The change of educational processes, learning and teaching in engineering education. Eurasia Journal of Mathematics, Science and Technology Education, 16(3), em1828. https:/ / doi.org/10.29333/ejmste/116034

More, M. (2018). Mathematics and engineering in real life through mathematical competitions. International Journal of Mathematical Education in Science and Technology, 49(2), 305-321. https:/ / doi.org/10.1080/0020739X.2017.1387297

Nizamutdinova, S. M., Lisitzina, T. B., Vorobyev, V. K., Prokopyev, A. I., Tararina, L. I., \& Sayfutdinova, G. B. (2019). Student views on downshifter lifestyle in urban environments. Humanities and Social Sciences Reviews, 7(4), 1196-1201.

Paiva, J. C., Leal, J. P., \& Queirós, R. (2020). Fostering programming practice through games. Information (Switzerland), 11(11), 1-20. https:/ / doi.org/10.3390 /info11110498

Papert, S. (1993). Mindstorms: children, computers, and powerful ideas. Basic Books.

Papert, S. (1996). An Exploration in the Space of Mathematics Educations. International Journal of Computers for Mathematical Learning, 1(1), 95-123. https:/ / doi.org/10.1007/BF00191473

Paterson, R. E. (2017). Intuitive cognition and models of human-automaton interaction. Human Factors: The Journal of the Human Factors and Ergonomics Society, 59(1), 101-115. https://doi.org/10.1177/ 0018720816659796

Perminov, E. A., Gadjiev, D. D., \& Abdurazakov, M. M. (2019). About relevance of fundamentalisation of mathematical training of students of the pedagogical directions during the digital era. Obrazovanie i Nauka, 21(5), 86-111. https:/ / doi.org/ 10.17853/1994-5639-2019-5-87-112
Petrova, S. O. (2021). Ethical behaviour of a teacher and students in the distance learning environment. Vestnik NCBŽD, 1(47), 17-23.

Piralova, O. F., Gerasimenko, S. A., Kuznetsov, V. V., Popova, O. V., Subbotin, G. V., Kolomyts, O. G., \& Mashkin, N. A. (2020). Gaming industry trends in new generation specialist training in university environment. Journal of Environmental Treatment Techniques, 8(3), 1132-1135.

Ponomarev, A., \& Dezhina, I. (2016). Approaches to the formulation of Russia's technological priorities. Foresight and STI Governance, 10(1), 7-15. https:/ / doi.org/10.17323/1995-459X.2016.1.7.15

Radović, S., Marić, M., \& Passey, D. (2019). Technology enhancing mathematics learning behaviours: Shifting learning goals from "producing the right answer" to "understanding how to address current and future mathematical challenges". Education and Information Technologies, 24(1), 103-126. https: / / doi.org/10.1007/s10639-018-9763-x

Sabirova, E., Zakirova, V., Valeeva, R. A., \& Mena, J. (2019). Educational platforms for children in teaching mathematics: Russian Case. ACM International Conference Proceeding Series, 594-599. https:/ / doi.org/10.1145/3362789.3362827

Sayed, F. (2017). ICT, mathematics and critical thinking. Turkish Online Journal of Educational Technology, 383385.

Semenykhina, O. V., \& Rudenko, Y. O. (2018) Problems of educating to programming of students and way of their overcoming. Information Technologies and Learning Tools, 66(4), 54-64. http:/ / doi.org/10.33407/itlt.v66i4.2149

Sirazetdinov, R. T. (2018). Mathematical models of risk in emergency situations. Vestnik NCBŽD, 4(38), 129134.

Skurikhina, J. A., Valeeva, R. A., Khodakova, N. P., \& Maystrovich, E. V. (2018). Forming research competence and engineering thinking of school students by means of educational robotics. Eurasia Journal of Mathematics, Science and Technology Education, 14(12), em1639. https://doi.org/ 10.29333 / ejmste/ 97827

Smirnov, E. I., Zykova, T. V., \& Tikhomirov, S. A. (2019). The management of school mathematical education with synergistic effect. Perspektivy Nauki $i$ Obrazovania, 37(1), 190-202. https://doi.org/ 10.32744/pse.2019.1.14

Soboleva, E. V., \& Perevozchikova, M. S. (2019). Features of training future teachers to develop and use mobile gaming applications with educational content. Perspektivy nauki i obrazovania - Perspectives of Science and Education, 41(5), 428-440. https:/ / doi.org/10.32744/pse.2019.5.30 
Soboleva, E. V., Suvorova, T. N., Zenkina, S. V., \& Gerasimova, E. K. (2020). The development of critical thinking through the involvement of pupils in competitive robotics (from work experience). Perspektivy nauki i obrazovania - Perspectives of Science and Education, 44(2), 268-284. https://doi.org/10.32744/pse.2020.2.21

Solodikhina, M. V., \& Solodikhina, A. A. (2019). Development of critical thinking of master's degree students using stem cases. Obrazovanie $i$ Nauka, 21(3), 125-153. https://doi.org/10.17853/19945639-2019-3-125-153

Urvanova, N. A. (2018). Model of development of mathematical thinking of students on the lessons of the disciplines of mathematical and natural science cycle. Innovative Development of Professional Education, 4(20), 39-45.

Usol'tsev, A. P., \& Antipova, E. P. (2019). Innovative activity of teachers - Myth or reality? The Education and Science Journal, 21(5), 9-41. https://doi.org/ 10.17853/1994-5639-2019-5-9-42

Valeeva, R. A. \& Bushmeleva, N. A. (2016). Forming analytical competency of higher school students. Mathematics Education, 11(8), 3137-3148.

Valeeva, R. A., \& Shakirova, K. B. (2015). Development of the future mathematics teachers' constructive skills. International Electronic Journal of Mathematics Education, 10(3), 221-229. https:/ / doi.org/10.12973 /ijese.2016.375a

Varshavskaya, E., \& Kotyrlo, E. S. (2019). Graduates in Engineering and Economics: Between Demand and Supply. Educational Studies Moscow, 2, 98-128. https: / / doi.org/10.17323/1814-9545-2019-2-98128

Wing, J. M. (2017). Computational thinking's influence on research and education for all. Italian Journal of
Educational Technology, 25(2), 7-14. https:/ / doi.org/ $10.17471 / 2499-4324 / 922$

Yung, O. C., Junaini, S. N., Kamal, A. A., \& Md Ibharim, L. F. (2020). I slash 100\%: Gamification of mathematics with hybrid QR-based card game. Indonesian Journal of Electrical Engineering and Computer Science, 20(3), 1453-1459. https://doi.org /10.11591/ijeecs.v20.i3.pp1453-1459

Yurkin, M. A., Shimitilo, V. L., Usacheva, T. V., \& Bataeva, K. S. (2020). Possible approaches to flood forecasting in information systems of EMERCOM of Russia with the use of mathematical models. Vestnik NCBŽD, 1(43), 131-139.

Záhorec, J., Hašková, A., \& Munk, M. (2010). Impact of Electronic Teaching Materials on Process of Education Results of an Experiment. Informatics in Education, 9(2), 261-281. https://doi.org/10.15388/ infedu.2010.19

Zaripova, I. M., Shaidullina, A. R., Upshinskaya, A. E., Sayfutdinova, G. B., \& Drovnikov, A. S. (2014). Modeling of petroleum engineers designtechnological competence forming in physicalmathematical disciplines studying process. American Journal of Applied Sciences, 11(7), 10491053. https:/ / doi.org/10.3844/ajassp.2014.1049.1053

Zeynivandnezhad, F., \& Bates, R. (2018). Explicating mathematical thinking in differential equations using a computer algebra system. International Journal of Mathematical Education in Science and Technology, 49(5), 680-704. https://doi.org/10.1080 /0020739X.2017.1409368

Zharko, L. N. (2020). Case-study as an innovative pedagogical technology in teaching activities of lecturer of additional professional education. Vestnik NCBŽD, 2(44), 49-56.

\section{http://www.ejmste.com}

